\title{
MODERNIZAR EL ESTADO. PLAN Y AGENTES DEL CAMBIO \\ EN LA ERA CAMBIEMOS. ARGENTINA, 2015-2019*
}

\author{
Jimena Caravaca \\ CIS-CONICET/IDES, Argentina \\ jimenacaravaca@gmail.com \\ Claudia Daniel \\ CIS-CONICET/IDES, Argentina \\ claudiadaniel@gmail.com \\ Julieta LenarduZZi \\ Universidad de Buenos Aires, Argentina \\ jlenarduzzi@gmail.com \\ Gabriela Mattina \\ CIS-CONICET/IDES, Argentina \\ gabrielamattina@yahoo.com.ar
}

\section{RESUMEN}

El artículo estudia la creación y la propuesta del primer Ministerio de Modernización de la Nación (MMN) de la Argentina. A poco de asumir la gestión a fines de 2015, el presidente Macri colocó a la modernización del Estado en el máximo escalafón institucional. El objetivo de este trabajo es comprender el carácter político de la empresa de modernización estatal encarada por la alianza Cambiemos en Argentina, a partir de conocer el contenido que le dio a la tarea modernizadora, las funciones y roles institucionales que construyó, y el perfil sociológico de los funcionarios que formaron parte del proyecto. Se presentan dos apartados: el primero dedicado a la estructura, recursos y líneas de acción del ministerio; el segundo enfocado en un estudio de trayectorias de sus funcionarios a partir de una base de datos de 192 perfiles que contempla tanto a las autoridades superiores, como a la Alta Dirección Pública.

$\mathrm{P}$

alabras clave: Modernización, Alta dirección pública, Trayectorias de carrera, Argentina.

La investigación para este trabajo fue financiada con fondos del proyecto PUE-

CONICET 005.

Revista de Gestión Pública | Volumen IX, Número 1 | Enero-Junio 2020 | issn 0719-1820

pp. $5-42$

DOI: $10.22370 /$ rgp.2020.9.1.2679 


\title{
MODERNIZING THE STATE: PLAN AND AGENTS OF CHANGE IN THE CAMBIEMOS ERA. ARGENTINA, 2015-2019
}

\begin{abstract}
The article examines the creation and objectives of Argentina's first Ministry of Modernization of the Nation (MMN). Soon after taking office at the end of 2015, President Macri positioned modernization of the state at the highest institutional level. The aim of this study is to understand the political nature of the efforts of Argentina's Cambiemos alliance to modernize the state, looking at the content it gave to the modernizing task, the institutional functions and roles it built and the sociological profile of the officials who participated in the project. The article is divided into two sections: the first focuses on the ministry's structure, resources and lines of action while the second examines the trajectories of its officials, using a database of 192 profiles that includes both the highest authorities and senior public management.
\end{abstract}

Keywords: Modernization, Senior public management, Career trajectories, Argentina. 


\section{INTRODUCCIÓN}

Desde hace ya algunos años que la implementación de procesos de modernización del sector público se convirtió en objeto de interés de investigadores y foco de debate en algunos países de América Latina. En este artículo nos proponemos contribuir a esas discusiones a partir de analizar la creación en 2015 del Ministerio de Modernización de la Nación (en adelante, MMN) en la Argentina y explorar su recorrido durante el gobierno de la alianza Cambiemos en la presidencia de Mauricio Macri (2015-2019). Dado que no se trata de la primera ni única experiencia de modernización estatal en la región latinoamericana, ¿qué factores lo vuelven un objeto interesante para el análisis social?

Investigaciones semejantes muestran que, en otros países de la región, objetivos similares fueron perseguidos a partir de programas modernizadores o planes maestros; en algunos casos, llegaron a ser institucionalizados bajo el formato de consejos o a lo sumo de departamentos ${ }^{1}$. Por tanto, la creación de una institución específica de rango ministerial es uno de los elementos que hace singular al caso argentino. Además, el MMN fue una de las dependencias estratégicas del gobierno de Macri que procuró no solo hacer una transformación económica promercado dirigida a potenciar una estructura primario exportadora en el país, sino que persiguió un cambio cultural que incluía los modos convencionales de pensar al Estado, sus deberes y funciones legítimas, las formas de gestión de lo público, el ethos de sus funcionarios y la propia relación que los ciudadanos entablan con él ${ }^{2}$.

El proyecto de modernización estatal que encarnó el ministerio tuvo tres facetas muy claras: una enfocada al rostro humano del Estado, a la planta de empleados públicos, en lo relativo a su identidad, conducta, capacitación y desempeño. La segunda cara de la modernización se presentó como una apuesta tecnológica: la de informatizar todas las operaciones involucradas en la gestión pública. Por último, la que se propuso incidir en los procesos de trabajo de la administración pública, mediante la incorporación de herramientas de gestión por resultados, monitoreo y evaluación. Este trabajo tiene como objetivo comprender el carácter político de la empresa de modernización encarada por el gobierno de Cambiemos en la Argentina, a través de conocer el contenido que le dio a la tarea modernizadora, las

1 Para profundizar, ver Pardo (2010), para México; González-Bustamante, Olivares, Abarca y Molina (2016), para Chile; Ramos y Casa (2018), para Uruguay; Gaetani (2000), para Brasil, entre otros.

2 Para valorar la centralidad de la cuestión estatal en la agenda de Cambiemos y el discurso presidencial, ver Presidencia de la Nación (2016). Para un análisis del lugar del Estado en el discurso presidencial, Buonfiglio (2016). 
funciones y los roles institucionales que construyó, y el perfil sociológico de los funcionarios que convocó.

Estudiar la conformación del MMN resulta relevante porque la empresa modernizadora de Cambiemos tuvo como rasgo saliente la reducción de la cuestión estatal a problemas de orden tecnológico relacionados con la administración del Estado (Bernazza 2016: 29, García Delgado 2017: 94), suponiendo la neutralidad política de esos instrumentos. Pero ningún proceso de modernización estatal es políticamente neutro, aun cuando sea presentado como una cuestión desideologizada. Asimismo, analizar la composición social de esta cartera es fundamental en la medida que se trata de conocer a los agentes que encauzan, en términos prácticos, los grandes objetivos políticos de reconfiguración estatal e intermedian en el proceso de moldear al "nuevo" empleado público, impregnados de sus convicciones, valores, intereses y lealtades.

A modo de balance, podemos decir que los procesos de reforma del Estado y la administración pública en la Argentina de los años 1980 y 1990 fueron los que concitaron mayor atención en el campo académico local (Ramírez Brouchoud 2009)33. Sin embargo, partiendo de un encuadre teórico similar, la reforma managerialista del gobierno de la Alianza (1999-2001) (Estévez 2003) y las estrategias de modernización del Estado posteriores a la profunda crisis de 2001, bajo el gobierno kirchnerista (Asinelli, Álvarez Travieso y Yodert 2008, Blutman 2013), también fueron analizadas, planteándose las condiciones y los límites de la aplicación de los principios de la new public management en el país. Trabajos académicos recientes subrayaron las similitudes del Plan de Modernización del Estado de la alianza Cambiemos con la escuela del NPM (Bernazza 2016). Otras lecturas entendieron el proyecto de transformación estatal de Macri como una "modernización de ruptura" en una etapa conceptualizada como de neoliberalismo tardío (García Delgado y Gardin 2017). En paralelo, otra línea de investigación se concentró en caracterizar sociológicamente al primer gabinete del gobierno de Cambiemos enfocándose en el perfil de sus principales figuras (Canelo y Castellani 2016a, 2016b, FLACSOCIFRA/CTA 2016). Desde otro ángulo, Etchemendy (2018) destacó el carácter errático del manejo administrativo general del Estado del presidente Macri, con ampliaciones de organigramas y al poco tiempo disoluciones, unificaciones seguidas de desdoblamientos. Todos cambios de corto plazo que parecían estar impulsados por una ideología neoliberal y proempresaria, antes que por metas fiscalistas, y sobre todo dirigidos a

3 Para un balance aún más amplio acerca de la producción académica de estudios sobre el Estado y la administración pública más reciente en la Argentina, ver Barros, Castellani y Gantus (2016). 
mermar las capacidades administrativas de áreas sobrevivientes del proyecto de un Estado social y protector en la Argentina.

Pese a existir un conjunto nutrido de indagaciones, el MMN ha sido hasta ahora un objeto escasamente estudiado. Aquí proponemos abordarlo no solo desde un punto de vista normativo e institucional, sino mediante el estudio de las trayectorias de los funcionarios jerárquicos que conformaron la cartera. En este trabajo exponemos algunos de los resultados del análisis de una base de datos que construimos con información de 192 funcionarios del MMN que ocupaban los cargos de ministro, secretario, subsecretario, director nacional, director general, director, coordinador y extraescalafonarios (con o sin rango en su resolución de designación) a principios de marzo de $2018^{4}$. Nuestro análisis contempla tanto a las autoridades superiores (ministro, secretarios y subsecretarios, pero también puestos extraescalafonarios, es decir, cargos políticos), como a la denominada Alta Dirección Pública (ADP) (directores nacionales, directores generales y coordinadores). Por medio de esta indagación buscamos detectar los principios de selección del personal, los criterios organizacionales y las prioridades que fueron definidas al momento de dar vida al ministerio. Creemos que este es un modo de acercarnos también a las concepciones subyacentes acerca de la administración pública, el empleo público y la idea misma de modernización estatal que caracterizó a la gestión Cambiemos. Confiamos en que esta mirada contribuya a la comprensión más profunda de sus objetivos de gobierno, en términos generales, en tanto nos enfocamos en un organismo creado apenas iniciada la gestión del presidente Macri a fin de 2015.

El análisis combinado de los cargos políticos superiores con los de la $\mathrm{ADP}$ nos permite ir un poco más allá de los responsables políticos principales de la cartera y tener en cuenta a funcionarios públicos con perfiles supuestamente más técnicos, burocracias especializadas o que ocupan posiciones intermedias, de confluencia entre los altos decisores gubernamentales y las burocracias operativas que ejecutan esas decisiones, pero que al mismo tiempo ejercen autoridad sobre cierta parcela del campo burocrático (Bourdieu 2014) y tienen personal a su cargo. La inclusión de esta ADP resulta significativa por varios motivos: en primer lugar, en tanto

4 En la investigación, se trabajó con más de cien variables referidas a las características socio-demográficas (como sexo y edad), la formación académica (nivel educativo alcanzado, título de grado y posgrado, disciplina, tipo de institución educativa, etc.), la trayectoria laboral (cargos ocupados en el sector público estatal y no estatal, el sector privado y organismos supranacionales) y los vínculos asociativos (participación en ONG, fundaciones y partidos políticos, entre otras organizaciones) de los funcionarios de la muestra. Para este artículo, seleccionamos algunas de ellas en función de su grado de consistencia y validez. 
son actores escasamente atendidos en las investigaciones sobre política pública y a los que se les otorga, sin embargo, una importancia crucial al momento de analizar la eficiencia de las administraciones, ya que se considera que su composición (formación, modo de acceso al cargo, vínculo con la política, etc.) es un factor condicionante para la implementación efectiva de reformas administrativas a largo plazo (Iacoviello, Llano y Ramos 2017). En segundo lugar, porque sus vínculos con las autoridades políticas superiores dan cuenta de los sistemas de reclutamiento al interior del Estado y con esto de las zonas grises entre política y técnica sobre las que nos interesa detenernos a través del estudio de trayectorias (Coutinho 2016).

La información necesaria para construir nuestra base fue recolectada en diversas fuentes online: boletines oficiales nacionales y provinciales, el sitio Infoleg.com, los perfiles de LinkedIn y currículums cargados por los propios funcionarios, perfiles en redes sociales, el sitio Buscardatos. com, sitios web de organismos gubernamentales, empresas, universidades y organizaciones sociales. Por otra parte, las entrevistas a las que pudimos acceder en el transcurso de nuestra investigación, como así también las realizadas y divulgadas por la prensa al funcionario de mayor rango del área, el ministro Andrés Ibarra, complementan nuestras interpretaciones de los datos.

\section{PROPUESTA DE MODERNIZACIÓN ESTATAL: ESTRUCTURA, RECURSOS Y LÍNEAS DE ACCIÓN}

\section{NuEVO MINISTERIO, ¿NUEVA AGENDA?}

El MMN nació con la gestión presidencial de Mauricio Macri, iniciada en diciembre de 2015, en el marco general de un incremento en el número de carteras promovido por el Presidente. La evaluación de la situación del Estado que hacía el gobierno recientemente electo fue sistematizada en un documento oficial de circulación pública titulado El estado del Estado. Diagnóstico de la administración pública en diciembre de 2015. En ese documento, la tarea de transformación estatal era presentada en los términos de una gesta refundacional, tal como lo hiciera el Presidente en la apertura de las $134^{\circ}$ sesiones ordinarias del Congreso Nacional:

[...] para hacer la Argentina del siglo XXI, tenemos que construir el Estado del siglo XXI, un Estado integrado, eficiente, inteligente, transparente, participativo e inclusivo, un Estado que esté, sobre todo, al servicio de la gente. Para construir ese Estado, creamos el primer Ministerio de Modernización de nuestra historia, que trabajará con 
cinco ejes principales: modernización administrativa, actualización de la infraestructura tecnológica, gobierno abierto, gobierno digital y, finalmente, una política que desarrolle los recursos humanos y que dé valor a la carrera pública (Presidencia de la Nación 2016: 19).

La creación de un ministerio nacional específico responsable de coordinar las acciones de transformación de las estructuras y las prácticas de la administración pública no tenía antecedentes en la Argentina. Sin embargo, la construcción histórica del problema del Estado como objeto de la agenda pública contaba con una trayectoria muy extensa. En el país, la problematización del Estado adquirió diferentes denominaciones a lo largo del siglo XX que fueron cambiando según los contextos económicos y políticos, y los climas intelectuales: desde la denuncia de la empleomanía (es decir, la retribución de favores políticos con cargos públicos) apenas alcanzada la democracia de masas (1916), hasta la noción del Estado elefantiásico e ineficiente fortalecida durante los años 1990, pasando por la apelación a la racionalización del gasto público para hacer al Estado apto para el desarrollo bajo el paradigma modernizador de los años sesenta. Si bien la cuestión del Estado aparece como una constante, sobre todo en la segunda mitad del siglo XX, problematizado desde diferentes discursos intelectuales, expertos y políticos, y al mismo tiempo sindicado como culpable de una amplia gama de problemas económicos del país (inflación, baja productividad, ineficiencia, rigidez del mercado, etc.), en 2015 la modernización del Estado, como tal, no constituía una demanda claramente articulada por un actor social en particular, ni se trataba de una cuestión ya estabilizada en la agenda. La creación del ministerio no tuvo como objeto atender a una demanda pública preexistente. Por el contrario, el gobierno de Cambiemos supo aglutinar una serie de reclamos dispersos que fueron utilizados como fundamento (demandas de participación ciudadana, transparencia, apertura de la información, agilidad y eficiencia en la gestión pública), que articuló y sintetizó bajo la etiqueta modernización, cerrando la ecuación política con un nuevo término de contenido más bien vago o indefinido. La demanda de modernización stricto sensu fue creada y viabilizada por el partido político en el gobierno, desde una posición oficial, con amplios márgenes para definir su contenido y en ausencia de un amplio debate 5 .

5 Los sindicatos de empleados públicos buscaron disputarle al gobierno el sentido de la modernización estatal -con muchos menores recursos y repercusiones en la esfera pública- sin demasiados resultados. Para ello organizaron en 2016 unas jornadas de discusión y la Asociación de Trabajadores del Estado (ATE) publicó el documento Repensando el Estado en el siglo XXI. Debates y propuestas para un Estado democrático y popular (ATE-CTA-CLATE- IDEPA 2016). 
El gobierno de Cambiemos tuvo la ventaja de conducir prácticamente solo el proceso de implementación de una agenda modernizadora del Estado, pues no se encontró con actores que pretendieran establecer o siquiera disputarle la definición del camino a recorrer en la empresa de transformación estatal. El gobierno se erigió a sí mismo como el portavoz del ciudadano argentino que, como el ciudadano global, "es parte y protagonista de ese cambio y reclama el compromiso del Estado para recibir bienes y servicios en consonancia con sus crecientes necesidades" (Compromiso Federal para la Modernización del Estado 2017: 1).

La creación del MMN y el Plan de Modernización, aprobado por el decreto presidencial $\mathrm{N}^{\circ} 434$, en 2016 fueron presentados públicamente por el gobierno como una entera novedad, como un esfuerzo inédito. Sin embargo, pueden trazarse líneas de continuidad hacia el pasado en más de una dirección. La primera de ellas tiene que ver con el deslizamiento jurisdiccional que operó Cambiemos con su empresa de modernización estatal. En los hechos, Plan y ministerio trasladaban a nivel nacional la experiencia de restructuración de la administración pública de la Ciudad Autónoma de Buenos Aires durante el gobierno local de Macri (20072015), al proponerse aplicar las mismas políticas a la administración pública central, organismos descentralizados, entidades autárquicas y empresas del Estado. En segundo lugar, la propia normativa que sancionaba el Plan de Modernización, reconocía que este incorporaba programas vigentes en la Argentina desde comienzos de siglo XXI, complementándolos con innovaciones propias del avance tecnológico de los últimos 15 o 20 años. Pero, a diferencia de planes previos, cuya prioridad había sido enfocarse en ciertas islas de modernización, el proyecto modernizador impulsado a fines de 2015 fue promocionado como un marco integral que procuraba revertir una situación del Estado considerada alarmante: un cuadro que se evaluaba compuesto por "estructuras organizativas anacrónicas", ausencia de "planificación estratégica", "división de funciones sin una lógica organizacional ni retribución acorde", un total "descontrol de la Administración Nacional" y falta de "planeamiento en la cantidad y calidad de las dotaciones", además de la incidencia del favoritismo político, la corrupción y la falta de transparencia, según sintetiza el informe oficial El estado del Estado (Presidencia de la Nación 2016: 34, 36). Se partía de diagnosticar que, luego de ańos de administración que se identificaba como populista, la Argentina contaba con un Estado "más grande pero desprofesionalizado y sobrepolitizado" incapaz de proveer bienes públicos de calidad, debido a que en la última década "las capacidades del Estado, en forma inversamente proporcional a su tamaño, mostraron una creciente debilidad en varias de sus atribuciones mínimas" (Presidencia de la Nación 2016: 37). 
En esta misma línea, el licenciado Andrés Ibarra, encargado de dirigir el MMN, planteaba en entrevistas públicas que la nueva gestión de gobierno se había encontrado con "un Estado muy oscuro y burocrático, con muchas complejidades". El contacto del ciudadano con la burocracia estatal era definido por el nuevo ministro como "una tortura" que el MMN se proponía erradicar a través de capacitación de los empleados públicos, de cursos de inducción para los ingresantes a la administración pública y de la inversión en tecnología e informatización que agilizaría y despersonalizaría los trámites que vinculan a la ciudadanía con el Estado.

Así, a principios de 2016, con el objetivo de mejorar la calidad y eficiencia de la gestión pública, el gobierno de Cambiemos se propuso implementar un Plan de Modernización del Estado que estaba estructurado en cinco ejes: 1) plan de tecnología y gobierno digital; 2) gestión integral de los recursos humanos; 3) gestión por resultados y compromisos públicos; 4) gobierno abierto e innovación pública; y 5) país digital. Bajo el paraguas de este nuevo plan, el MMN no planteaba una agenda de trabajo del todo novedosa ni en el plano de las actividades propuestas (digitalización, informatización, capacitación del empleado público) ni en las herramientas managerialistas que pretendía integrar al funcionamiento de la administración pública como parte de su política de gestión (gestión por resultados, evaluación de desempeńo, incentivos económicos, tableros de control, etc.). Tampoco reconocía los antecedentes existentes, ni enmarcaba sus propuestas de profesionalización de los recursos humanos del Estado en las discusiones que se venían desarrollando en el país en materia del estatuto del empleado público en los años previos (Bernazza 2016).

En la propuesta de modernización estatal de Macri prevalecían concepciones que estaban presentes desde el desembarco del NPM en la Argentina, puesto que desde mediados de los ańos 1990 la agenda modernizadora había sido abrazada por gobiernos de diversas tendencias ideológicas (desde la Alianza, 1999-2001, al kirchnerismo, 2003-2015), aunque tal vez de manera menos explícita o desplazada de los primeros planos (Estévez 2001 y 2003, Blutman 2009). La terminología utilizada en el Plan de Modernización de Cambiemos encontraba rápidamente eco en programas anteriores financiados por organismos internacionales en la Argentina ${ }^{6}$ cuando refería a: la eficacia y la transparencia; la necesidad de facilitar la interacción entre ciudadanos y organismos públicos; la gestión

6 Desde 2000, existía en el país un Plan de Modernización de la Administración Pública que estaba bajo responsabilidad de la Jefatura de Gabinete de Ministros financiado con fondos del Banco Internacional de Reconstrucción y Fomento (BIRF). Sucesivas reformulaciones de este plan se dieron en el gobierno de Néstor Kirchner (20032007) haciendo uso de esta línea de crédito que se encontraba abierta. 
por resultados y la eficiencia de la administración pública; el gobierno abierto para la evaluación y el control de los programas estatales y las instituciones públicas. En lo relativo al empleo público, específicamente, la propuesta de Cambiemos también renovaba viejos anhelos: tener una administración integral del personal unificada, mejorar la eficiencia de los recursos humanos del Estado y controlar el cumplimiento de metas, y simultáneamente, desarrollar habilidades gerenciales, aplicar instrumentos de gestión por resultados, capacitar y profesionalizar.

Sin embargo, la percepción del carácter rupturista que expresan los objetivos modernizadores de Cambiemos formaba parte de la cosmovisión de los funcionarios involucrados en el área. Al referirse a cuestiones como la agenda digital, la política integral de tecnología y de recursos humanos que procuraba llevar adelante el MMN, un funcionario que hemos entrevistado recapituló los ańos de trabajo en la cartera como si todo hubiera sido "empezar de cero". Este mismo funcionario presentaba a Ibarra como el gran gestor de "un ministerio de gente de acción" relato, la modernización quedaba identificada como una tarea apolítica y, por eso mismo, positiva. La inclinación a opacar el carácter político de la modernización impulsada tenía tanto de estrategia de comunicación como de autopercepción.

\section{UNA CORTA HISTORIA DE EXPANSIÓN Y REPLIEGUES}

En sus comienzos, la creación del MMN fue públicamente identificada con un mero programa fiscalista de reducción estatal. Tanto es así que, durante los primeros tiempos de su gestión, el referente máximo de la cartera, Andrés Ibarra, fue presentado por la prensa como el "ministro de la tijera", el "gran auditor", el "ministro que ajusta a los ministros". Sin embargo, el abanico de tareas proyectadas era más amplio y el MMN estuvo conformado, desde el principio, por cuatro secretarías: 1) Secretaría de Empleo Público, a cargo del diseño y la implementación de políticas de desarrollo del empleo público, con eje en la capacitación y la carrera profesional; 2) Secretaría País Digital, dedicada a la inclusión digital y a agilizar los trámites que vinculan a la ciudadanía con los distintos niveles de la Administración Pública; 3) Secretaría de Gestión e Innovación Pública, encargada de diseñar herramientas para un nuevo tipo de gestión que incorporara la transparencia y la participación ciudadana; y 4) Secretaría de Modernización Administrativa, con la misión de agilizar y hacer más eficiente la gestión cotidiana a través de la incorporación de tecnologías (firma digital, trámites a distancia, portales web, etc.). Esa estructura inicial

7 Entrevista con funcionario del área de Relaciones Institucionales, realizada el 14 de agosto de 2018. 
no difería sustancialmente de las líneas que fueron definidas en la Jefatura de Gabinete de Ministros (JGM) que, desde el año 2000, había tenido a su cargo los sucesivos programas modernizadores ${ }^{8}$. Lejos de mostrarse como una estructura rígida, el MMN estuvo sujeto a modificaciones recurrentes en su corta vida institucional. A menos de dos ańos de existencia, en septiembre de 2017, las secretarías pasaron a ser cinco a partir de la incorporación bajo la órbita del MMN de lo que había sido el Ministerio de Comunicaciones?. Así acaparó, además de los temas de empleo público, gestión, informatización y modernización que provenían de la vieja secretaría de Modernización de JGM, grandes estructuras bajo su responsabilidad. Luego, en septiembre de 2018, el MMN volvió a ser objeto de modificaciones cuando, por decisión del presidente Macri (Decreto $\mathrm{N}^{\circ}$ 801/2018), descendió de jerarquía junto a otras carteras para convertirse en secretaría ${ }^{10}$.

Este rasgo de inestabilidad merece ser analizado desde distintos ángulos: al tratarse de un organismo de reciente creación, los cambios pueden haber atendido a exigencias de la vida práctica del ministerio. Es decir, la experiencia que se fue acumulando pudo haber redefinido las propias tareas del ministerio e indicado la necesidad de ajustes en las formas organizacionales para llevarlas a cabo. Sin embargo, el imperativo de adaptación continua pudo estar manifestando también lo aventurado del proyecto de creación del MMN. Es decir, al mismo tiempo que se daba la espalda a lo actuado en materia de modernización estatal desde el Poder Ejecutivo Nacional hasta entonces, el MMN se ponía en funcionamiento a partir de tareas y competencias derivadas de lo hecho previamente en la Ciudad de Buenos Aires. Sin embargo, esa experiencia local no podía de ningún modo resultar representativa de lo que el MMN debía afrontar a nivel nacional, dada la distancia que existía tanto en términos de escala como de las condiciones sociales, económicas y demográficas de la población a la que se orientaba ahora. La labor del nuevo ministerio exponía cotidianamente esa dificultad y ello podría explicar, en buena medida, las sucesivas redefiniciones del organigrama.

8 En el ámbito de la JGM, la Secretaría para la Modernización del Estado incluía al Instituto Nacional de la Administración Pública, la Oficina Nacional de Contrataciones, y una Subsecretaría de la Gestión Pública, que incluía tres oficinas nacionales: de Innovación y Gestión, de Tecnologías de la Información y de Empleo Público..

9 La antigua Secretaría de Comunicaciones había adquirido estatus ministerial en 2015 y, en julio de 2017, se lo disolvió por el decreto Nº513/2017 que modificó la Ley de Ministerios.

10 Según el decreto que creó la Secretaría de Modernización, ella siguió encargada de ejecutar los planes, programas y proyectos del área de su competencia, pero de allí en adelante conforme las directivas que impartiera la JGM. Ibarra fue nombrando vicejefe de gabinete. 
Los recursos financieros asignados a la cartera modernizadora no estuvieron contemplados en el ejercicio presupuestario de 2016 por haber sido una entera creación del nuevo gobierno apenas en funciones. Si el presupuesto del MMN fue incrementándose con el correr de los años, como muestra el cuadro que presentamos a continuación ${ }^{11}$, no significó un crecimiento de recursos en términos reales en el último año de la gestión de Macri. Es decir, sus recursos presupuestarios se expandieron entre 2017 y 2018, pero se redujeron entre 2018 y 2019.

Tabla 1: Evolución del Presupuesto del MMN entre 2016 y 2019, en términos absolutos, relativos y en relación al presupuesto del PEN

\begin{tabular}{|c|c|c|c|c|c|}
\hline Año & $\begin{array}{l}\text { Presupuesto del } \\
\text { MMN } \\
(\$)\end{array}$ & $\begin{array}{c}\text { Variación } \\
\text { i.a. }\end{array}$ & $\begin{array}{l}\text { Variación } \\
\text { i.a. } \\
\text { en } \\
\text { términos } \\
\text { reales** }\end{array}$ & $\begin{array}{c}\text { Presupuesto } \\
\text { total del Poder } \\
\text { Ejecutivo Nacional } \\
\text { (excluyendo } \\
\text { pago de deudas y } \\
\text { obligaciones del } \\
\text { Tesoro) }\end{array}$ & $\begin{array}{c}\text { Participación } \\
\text { porcentual } \\
\text { del MMN }\end{array}$ \\
\hline 2016 & 708.037 .016 & - & & 752.193 .582 .888 & $0,094 \%$ \\
\hline 2017 & 2.054 .969 .107 & $190,2 \%$ & $105,8 \%$ & 768.935 .949 .524 & $0,267 \%$ \\
\hline 2018 & 2.956 .365 .031 & $43,9 \%$ & $14,1 \%$ & 837.186 .926 .676 & $0,353 \%$ \\
\hline 2019 & $3.200 .701 .839 * * *$ & $8,3 \%$ & $-25,6 \%$ & 850.011 .948 .320 & $0,377 \%$ \\
\hline
\end{tabular}

**Para el cálculo se tuvo en cuenta el Índice de Precios al Consumidor (IPCBA) de la Dirección General de Estadística y Censos, Ministerio de Economía y Finanzas del Gobierno de la Ciudad de Buenos Aires. *** Corresponde a la Secretaría de Gobierno de Modernización. Fuente: Elaboración propia en base a Ministerio de Hacienda (2016, 2017a, 2017b, 2018a, 2018b y 2019).

Si tomamos en cuenta la distribución del Presupuesto destinado a las distintas áreas del Poder Ejecutivo Nacional, excluyendo el pago de deudas públicas y obligaciones del Tesoro (Tabla 1), el monto asignado al funcionamiento del MMN era muy poco significativo. Durante todos los años de gestión de Macri, fue el ministerio que percibía la porción más pequeña de los recursos financieros distribuidos entre el gabinete, seguido solo por Turismo, en los tiempos en que esta área existió como ministerio en 2017 y 2018, y por el Ministerio de Comunicaciones en 2017. Si bien con el incremento presupuestario de 2017 a 2018 el peso relativo del MMN creció, permaneció bastante constante al tomar en cuenta su participación en la distribución de recursos en 2018 (0,353\%) y 2019 (0,377\%). Es

11 Agradecemos la colaboración del licenciado Marcelo Bruchanski, becario del PUECONICET 005, en la elaboración de los cuadros sobre el presupuesto asignado al MMN. 
decir, que el lugar de Modernización en relación a otras carteras no se vio recortado en esos años pese a haber descendido a secretaría.

El MMN fue dotado de recursos para emprender la gesta modernizadora y fortalecer su autoridad vis-à-vis otros ministerios, porque tomaba decisiones que afectaban esas otras carteras (en relación a la incorporación o la movilidad de empleados, en la elección de los sistemas de gestión interna, en la definición de protocolos de procedimiento). A diferencia de los ministerios de tipo vertical, según la clasificación de Quermonne (citado en González-Bustamante et al. 2016) como Salud, Desarrollo Social, Justicia o Defensa, que operan sobre sectores específicos y tienen sus propios públicos o clientelas a las que orientan sus acciones, el MMN era una cartera de tipo horizontal que trabajaba de manera transversal a los ministerios, coordinando además con distintas instancias y niveles jurisdiccionales de la administración pública. Sus destinatarios eran más bien indiferenciados: iban desde la totalidad de la planta de empleados públicos a la ciudadanía, en general. Dada la transversalidad de su trabajo, el accionar del MMN chocó con los intereses e iniciativas de otras áreas administrativas dirigidas por funcionarios políticos del mismo gobierno de Cambiemos. Esto le trajo dificultades para imponer su (pretendida) autoridad en ciertas materias, como demuestran las idas y vueltas en la implementación de programas de gestión. En una entrevista, una ex funcionaria del MMN dejó en evidencia las tensiones que emergieron entre dependencias: algunos ministerios decidieron implementar un programa de control de asistencia del personal de la administración pública que no interactuaba automáticamente con el establecido por el MMN. De esta forma, el organismo cumplía con la exigencia del MMN de implementar un sistema de control del presentismo, pero reservaba para sí la información que no podía ser cruzada con el sistema de recursos humanos promovido desde el MMN. Así, conservaba ciertos márgenes de autonomía y capacidad de control al interior de su propia repartición.

Si se analiza la distribución del presupuesto del MMN entre los ejes definidos por el Plan de Modernización, expresados a través de sus programas $^{12}$, se observa que casi la tercera parte de los recursos disponibles del MMN fueron invertidos en la política de desarrollo de los recursos humanos del Estado en los ańos 2017 y 2019, representando una cuarta parte en 2018. En cambio, la línea de fortalecimiento de la gestión e innovación pública fue la que proporcionalmente recibió menos recursos del MMN en todo el período. El programa de modernización administrativa

12 Aunque el MMN se convirtió en Secretaría de Gobierno en 2018, mantuvo una denominación similar para los programas en el presupuesto, aunque la Unidad Ejecutora de esos fondos pasó a ser la Secretaría de Gobierno de Modernización de la JGM. 
redujo su participación en la distribución interna de recursos entre 2017 y 2019, pero se mantuvo entre el 11\% y el 15\% de lo asignado al MMN.

Tabla 2: Participación de los programas del MMN en el presupuesto total del ministerio, en pesos y porcentaje

\begin{tabular}{|c|c|c|c|c|c|c|c|}
\hline Denominación & Unidad Ejecutora & 2017 & & 2018 & & 2019 & \\
\hline $\begin{array}{l}\text { Actividades } \\
\text { Centrales }\end{array}$ & & 425.866 .196 & 20,7 & 334.385 .349 & 11,3 & 505.066 .868 & 15,8 \\
\hline $\begin{array}{l}\text { Integración de la } \\
\text { Infraestructura }\end{array}$ & $\begin{array}{c}\text { Subsecretaría } \\
\text { de Tecnología y }\end{array}$ & 338.924 .576 & 16,5 & 349.102 .166 & 11,8 & & \\
\hline Tecnológica & Ciberseguridad & & & & & 557.639 .495 & 17,4 \\
\hline $\begin{array}{c}\text { Impulso a la } \\
\text { Iniciativa País } \\
\text { Digital }\end{array}$ & $\begin{array}{c}\text { Secretaría País } \\
\text { Digital }\end{array}$ & 159.497 .737 & 7,8 & 220.618 .076 & 7,5 & & \\
\hline $\begin{array}{l}\text { Desarrollo de los } \\
\text { Recursos Humanos } \\
\text { del Sector Público }\end{array}$ & $\begin{array}{c}\text { Secretaría de } \\
\text { Empleo Público }\end{array}$ & 626.121 .427 & 30,5 & 781.413 .349 & 26,4 & 969.261 .612 & 30,3 \\
\hline $\begin{array}{c}\text { Fortalecimiento } \\
\text { de la Gestión e } \\
\text { Innovación Pública }\end{array}$ & $\begin{array}{l}\text { Secretaría } \\
\text { de Gestión e } \\
\text { Innovación } \\
\text { Pública }\end{array}$ & 193.504 .317 & 9,4 & 281.965 .659 & 9,5 & 232.513 .938 & 7,3 \\
\hline $\begin{array}{l}\text { Modernización } \\
\text { Administrativa }\end{array}$ & $\begin{array}{c}\text { Secretaría de } \\
\text { Modernización } \\
\text { Administrativa }\end{array}$ & 311.054 .854 & 15,1 & 335.799 .371 & 11,4 & 377.505 .301 & 11,8 \\
\hline $\begin{array}{l}\text { Formulación y } \\
\text { Coordinación } \\
\text { de Políticas de } \\
\text { Comunicaciones }\end{array}$ & $\begin{array}{c}\text { Secretaría } \\
\text { Tecnologías de la } \\
\text { Información y las } \\
\text { Comunicaciones }\end{array}$ & 0 & 0 & 180.081 .061 & 6,1 & 49.291 .764 & 1,5 \\
\hline $\begin{array}{c}\text { Asistencia } \\
\text { Financiera a } \\
\text { Empresas Públicas }\end{array}$ & $\begin{array}{l}\text { Ministerio de } \\
\text { Modernización }\end{array}$ & 0 & 0 & 473.000 .000 & 16 & 509.422 .861 & 15,9 \\
\hline Total & 2.054 .969 .107 & 2.054 .969 .107 & 100 & 2.956 .365 .031 & 100 & 3.200 .701 .839 & 100 \\
\hline
\end{tabular}

Fuente: Elaboración propia en base a Ministerio de Hacienda (2016, 2017a, 2017b, 2018a, 2018b y 2019).

A lo largo de toda su existencia, los recursos del MMN provinieron fundamentalmente de fuentes internas de financiamiento; estas cubrieron la totalidad de los gastos en 2017, el 93\% en 2018 y el $94 \%$ en 2019 . La reducida proporción de aportes externos estaba vinculada básicamente a dos créditos: uno del Fondo Financiero para el Desarrollo de la Cuenca del Plata (Fonplata), aprobado en marzo de 2017; el otro otorgado por el BIRF, aprobado en agosto del mismo año. Estas líneas de financiamiento externo se orientaron a infundir fondos a todos los programas en marcha, a excepción del vinculado al desarrollo de los recursos humanos del sector público.

Por otra parte, el gobierno impulsó la creación del Consejo Federal de Modernización e Innovación en la Gestión Pública (COFEMOD) que 
promovió el Compromiso Federal para la Modernización del Estado (suscripto entre el Estado nacional y las provincias el 17 de abril de 2017) como instrumento para involucrar a las administraciones públicas provinciales en la consecución de la modernización estatal. Este acuerdo contemplaba objetivos, planes y metas a alcanzar entre 2017 y 2019 de manera que la administración central pudiera controlar su implementación en los gobiernos subnacionales. Para su puesta en funcionamiento las provincias contrataron a organizaciones públicas como el Centro de Implementación de Políticas Públicas para la Equidad y el Crecimiento (CIPPEC) que colaboró en el diagnóstico y las propuestas que implica el Compromiso Federal (CIPPEC sin fecha).

En síntesis, como fue mencionado, entre 2015 y 2019, el MMN conoció etapas de expansión institucional y de acumulación de recursos humanos y financieros, pero vivió también momentos de repliegue con la pérdida del rango ministerial. Reconocer este repliegue, sin dejar de sostener que se trata de un organismo estratégico para el gobierno de Cambiemos merece, al menos, un intento de explicación. En este sentido, uno de nuestros entrevistados resignificó la transversalidad que caracteriza a la actuación del MMN, desde su gestación, como la capacidad del organismo de "estar en todos lados", sin que ello fuera demasiado visible a los ojos de la ciudadanía. A su entender, la tarea de Modernización "tiene un impacto gigante al interior [del Estado], pero que no se ve" en la esfera pública. El supuesto carácter imperceptible de las actividades encargadas al MMN, pudo haber estado entre las razones que lo destinaron a formar parte del lote de organismos que perdieron estatus ministerial para pasar a ser secretarías de gobierno en 2018. Aun cuando tal reorganización de la cartera estuviera guiada principalmente por la finalidad del Presidente de dar un mensaje de austeridad a la sociedad y a los organismos financiadores internacionales, sin haber afectado en realidad el peso relativo del área de modernización al interior del Poder Ejecutivo cuando se considera la distribución de recursos presupuestarios, el lugar poco visible aunque omnipresente del organismo lo convertía en un blanco fácilmente elegible para la reubicación planteada por el decreto $\mathrm{N}^{\circ} 801 / 2018$.

Por otra parte, teniendo en cuenta los avatares del Ministerio de Modernización de la Ciudad Autónoma de Buenos Aires (CABA), antecedente inmediato y modelo para la creación de su par nacional, el final del MMN era previsible. En la Ciudad de Buenos Aires y ante el vacío de autoridad que significó que su titular, Andrés Freire, fuera elegido para ocupar un cargo electivo, el Ministerio de Modernización local fue desguazado y sus partes absorbidas por diversas áreas (ministerios de Finanzas, de Gobierno, Vicejefatura de Gobierno y Ministerio de Desarrollo 
Urbano), aunque mayoritariamente por la cartera de Educación, que desde marzo de 2018 se denominó Ministerio de Educación e Innovación. Es decir, las funciones asignadas a Modernización se repartieron entre organismos, pero no desaparecieron. A partir de esta experiencia, podemos sostener que los procesos de modernización parecen ser altamente dependientes de algunas figuras que los encarnan y les dan forma. La ausencia de una definición previa acerca de qué es la modernización estatal, o qué se espera de ella, implicó que no estuviera predefinido el perfil de los funcionarios que se consideraban apropiados para llevar adelante la tarea modernizadora, porque el contenido de la función a desarrollar tampoco lo estaba. Antes bien, todo parece indicar que, como en el caso de Andrés Ibarra, lo que resultó determinante al momento del nombramiento fueron los vínculos de lealtad y confianza; de allí la relevancia de indagar en los perfiles, trayectorias y formas de reclutamiento de quienes condujeron la tarea modernizadora en la Argentina de Cambiemos.

\section{TRES FRENTES DE ACCIÓN}

Bajo el amplio paraguas de la modernización, el MMN pudo conjugar una serie de acciones diversas. A continuación, hacemos referencia a los contenidos específicos que adquirió la empresa modernizadora en el gobierno de Cambiemos a partir de las tres facetas que definieron el proyecto del MMN presentadas al inicio de este artículo.

En primer término, en relación con la planta de empleados públicos, su profesionalización y capacitación fue uno de los propósitos manifiestos de la gestión. En ese sentido, advertimos un desplazamiento de la oferta de cursos brindados por el Instituto Nacional de la Administración Pública (INAP) que incluyó, junto a programas de formación básica (finalización de la educación media o manejo de paquetes informáticos como Word y Excel, por ejemplo), cursos sobre liderazgo, Big data y machine learning, orientados hacia la Alta Dirección Pública. Esta formación específica para la ADP estaba vinculada a una concepción particular que motorizaba al MMN: la modernización de los modos de hacer en el Estado no dependía de la adopción universal por parte del conjunto del funcionariado de los criterios de gestión propuestos, sino de que algunos "líderes de cambio" (Ministerio de Modernización 2017) los encarnaran en sus equipos de trabajo. Junto a esta capacitación destinada a la ADP, el INAP ofrecía inducciones para nuevos empleados, dictadas tanto desde su plataforma virtual como a través de folletos como la Guía de bienvenida al Estado (Secretaría de Modernización 2019) donde se presentaban los deberes y derechos de cada una de las partes (empleados y empleador, es decir, el Estado) y se brindaba información y contactos útiles para la vida laboral, 
del mismo tenor (lenguaje y contenido) que el de una empresa privada donde este tipo de práctica inicial es habitual.

Por otra parte, el MMN llevó a cabo análisis de dotaciones de personal, herramienta presentada a la sociedad como una guía para orientar la reducción del número de empleados públicos, y creó una dirección nacional a tal efecto en el marco de la Secretaría de Empleo Público. Sin embargo, durante la gestión Cambiemos, el devenir de la cifra de empleados públicos muestra algunas particularidades. En primer término, el tamaño de la administración pública nacional creció apenas iniciada la gestión, cuando se modificó la estructura ministerial que pasó de 18 a 22 carteras, con el consecuente incremento de cargos políticos y públicos. Luego, en septiembre de 2018, el cambio de jerarquía de varios ministerios que, como vimos, afectó a Modernización, terminó por dejar en pie un total de once ministerios, a la vez que eliminó un número significativo de secretarías y direcciones con el objetivo explícito de reducir un 25\% la planta política de la administración pública nacional. Esta cifra coincidía con el aumento ocasionado por la ampliación de carteras ministeriales al inicio de la gestión (Gasparin y Diéguez 2018). Las cifras totales del empleo indican que se redujeron 24.000 puestos de trabajo entre 2015 y 2018, aunque la proporción mayoritaria de esa reducción (alrededor de 18.000 cargos, es decir más del 75\% de los mismos) se explica por el traspaso de las fuerzas de seguridad de la administración pública nacional a la órbita del Gobierno de la Ciudad de Buenos Aires (Gasparin y Dieguez 2018: 8). Es decir, durante la gestión del presidente Macri no hubo una disminución significativa del empleo público, antes bien una descentralización y una reducción de los cargos de ADP que la misma gestión había sumado. Tanto la ampliación como la reducción de cargos tuvieron epicentro en los puestos políticos, específicamente en los cargos extraescalafonarios o fuera de nivel dentro de la ADP, a los que se accede por nombramiento directo del Poder Ejecutivo Nacional, pero que se encuentran excluidos del Sistema Nacional de Empleo Público, es decir, "son instrumentos para designar personal político fuera de la estructura formal" (Gasparin y Diéguez 2018: 4). En este sentido, cabe mencionar que el MMN concentraba una proporción significativa de la totalidad de cargos fuera de nivel de la gestión Cambiemos ${ }^{13}$, lo que subraya el carácter político del MMN a la vez que revela la importancia de los vínculos de lealtad y cercanía al momento de la contratación. Si bien, en las últimas décadas, la experiencia de puesta en práctica de los preceptos del NPM en Latinoamérica estuvo asociada a enclaves profesionales y técnicos que las llevaron adelante, este parece ser un signo de debilidad antes que de

13 El MMN concentró un 11\% de los puestos extraescalafonarios creados entre 2015 y 2017 (Gasparin y Diéguez 2018). 
fortaleza, en tanto esos cargos políticos tendieron a ser discontinuados con los cambios de gestión, dejando truncos los proyectos. La forma de garantizar continuidad en las políticas públicas, según señala Ramírez Brouchoud (2009: 131), entre otros, es apostar por la consolidación de un servicio civil de carrera; apuesta que el MMN llevó adelante con pocos resultados. La meta fijada por el MMN entre enero de 2017 y diciembre de 2019 (10.499 cargos) había sido completada en menos de la mitad (46\%) a seis meses de cumplirse el plazo (Jefatura de Gabinete de Ministros sin fecha).

La segunda faceta del MMN, la relacionada con la apuesta tecnológica, contemplaba entre sus contenidos específicos la implementación del expediente electrónico, la firma digital, los trámites a distancia, junto con la inversión en infraestructura para la conectividad nacional, como el Plan Nacional de Fibra Óptica, por ejemplo, indispensable para poner en funcionamiento esos programas a nivel federal. Además, se lanzó un portal web nacional que presentaba contenidos unificados y que se planteaba como la puerta principal del contacto entre la ciudadanía y el Estado. Un contacto que la gestión Cambiemos promovió, en tanto allí concentraba información vital para todos los trámites públicos (el sitio, por ejemplo, incluía una ventanilla de turnos unificada para todos los trámites públicos, incluso para aquellos que requerían una instancia presencial) (Presidencia de la Nación sin fecha). Ese tipo de dispositivos fomentaba un vínculo con el Estado que era individual y virtual ${ }^{14}$. Al mismo tiempo, suponía una ciudadanía modelo con un piso de recursos (técnicos, en tanto requiere dispositivos y conectividad, pero también de conocimientos, para llegar a la información que necesita, que a su vez supone cierto piso de capitales económicos y culturales propios de los sectores más acomodados de la sociedad) para que su relación con el Estado fuera fructífera.

El tercer y último aspecto que aquí enumeramos del accionar del MMN estaba relacionado con los procesos de la gestión pública, es decir, lo relativo a las prácticas internas al Estado. En este sentido, el MMN promovía la gestión por resultados. Este enfoque era definido como un "sistema de información que constantemente pu[diera] generar evidencias sobre los avances o desvíos en la consecución de metas comprometidas, tanto para la toma de decisiones interna como para la rendición de cuentas a la ciudadanía" (Ministerio de Modernización 2017: 5). Producto de la nueva gestión pública, tal como era recuperado en los documentos públicos que la promocionaban, la gestión por resultados suponía planificación,

14 "Activamos el diálogo entre el Estado y vos para generar en conjunto políticas públicas que respondan a las demandas actuales de nuestro país" (Jefatura de Gabinete de Ministros sin fecha).. 
evaluaciones intermedias a partir de indicadores seleccionados y redefinición de objetivos sobre la misma práctica. Se trataba de "maximizar la creación de valor público y los resultados para el ciudadano", antes que de velar por los procedimientos formales (Ministerio de Modernización 2017: 8). El modelo de gestión propuesto por el MMN combina la gestión por resultados con el agilismo, un enfoque para la gestión dinámica de proyectos surgido en los años noventa en el seno de la comunidad de desarrolladores de software, de quienes tomaba toda una jerga específica (sprint, por ejemplo, para referirse a las etapas de trabajo que forman parte de un proyecto, pero también lean start-up, agile scrum). Lo que los desarrolladores plantearon entonces como la necesidad de colaboración estrecha con el cliente (frente al modelo previo que era cuestionado porque el cliente se reencontraba con el equipo de desarrollo al momento de la entrega de un producto final ya cerrado), fue retomado por la traducción del Agilismo para la gestión pública como la necesidad de contacto con la población objeto de la intervención. Esto suponía darle voz a la población en el diseño y redefinición de una política, pero también otorgarle una responsabilidad en la consecución de sus objetivos. Para esta manera de concebir la gestión pública, la evaluación sistemática resultaba fundamental, en tanto permitía el monitoreo constante y el redireccionamiento temprano de los cursos de acción. De allí que los tableros de control interno y de monitoreo externo de cumplimiento de metas (tablero de gestión o tablero ciudadano) se postularan como una herramienta central.

El Tablero Ciudadano (que podía verse en los sitios web de todos los ministerios) presentaba datos estadísticos de la gestión a la vez que hacía recaer el seguimiento de las políticas en el control ciudadano ${ }^{15}$. Esta herramienta llevaba implícita una concepción particular de la ciudadanía: la suponía conectada, decidida a ejercer el control y a evaluar la gestión. Es decir, el interlocutor imaginado era una ciudadanía atomizada, pero capaz de leer información estadística, con tiempo para hacerlo. Esta herramienta, por otro lado, no tuvo como contrapartida la formación de esa ciudadanía digital por parte del Estado. La adopción de este tipo de estándar internacional le permitía al gobierno pertenecer a asociaciones internacionales, escalar en rankings de gobierno abierto y transparencia, entre otros, y mostrarse así como parte integrante del mundo moderno. Con esto, además, abría las puertas al diálogo con los organismos financiadores de crédito, porque hablaba el mismo idioma ${ }^{16}$.

15 "Estos son los proyectos prioritarios en los que trabaja la Secretaría de Gobierno de Modernización. Participá en el análisis y seguimiento de nuestras acciones y resultados" (Jefatura de Gabinete de Ministros sin fecha).

16 El vínculo entre los organismos internacionales de crédito y la expansión del new public managment desde los ańos 1990 ha sido analizado por Ramírez Brouchoud (2009), Prats i Català (2005) y López (2005). 


\section{EL PERFIL SOCIAL DE LOS AGENTES MODERNIZADORES}

En esta sección nos proponemos analizar el perfil sociológico del conjunto de funcionarios de nivel jerárquico - desde el vértice de la pirámide, es decir, la posición de ministro, hasta el rango de coordinación- que conformaba el MMN. Nuestro objetivo es describir la composición demográfica, las trayectorias educativas y ocupacionales de estos funcionarios públicos. En tanto el ministerio fue una creación institucional de la gestión Cambiemos, consideramos que este tipo de análisis nos abre una ventana privilegiada para dar cuenta tanto de los mecanismos de reclutamiento del gobierno como de las áreas profesionales y técnicas que fueron evaluadas positivamente en el proceso de construcción del MMN. Asimismo, nos permite identificar la reproducción de lógicas previas propias del Estado argentino, fuertemente criticadas por los líderes políticos del partido mientras estuvo en el gobierno.

A fines de 2015, el presidente Macri designó como ministro para liderar la tarea modernizadora a Andrés Ibarra, por entonces de 58 años. Ibarra era un estrecho colaborador de su gestión en la Ciudad Autónoma de Buenos Aires al que se le pedía trasladar su experiencia y su equipo al ámbito nacional. El primer Ministro de Modernización de la Argentina es Licenciado en Ciencias Económicas por la Universidad Católica Argentina (UCA), con estudios de posgrado en la Universidad de Stanford. Realizó sus estudios secundarios en el Liceo Militar General San Martín de la provincia de Buenos Aires. Se había desempeñado como Ministro de Modernización en CABA entre 2011 y 2015, y antes ocupó otros puestos en el gobierno local en las carteras Hacienda y Educación desde el comienzo de la gestión de Macri en 2007. Ibarra inició su actividad en el sector público con la llegada de Mauricio Macri al gobierno en la Ciudad. Para entonces, tenía hecha toda una carrera en el ámbito privado: había ingresado al grupo Macri a fines de la década de 1970 y se desenvolvió en distintos puestos de las empresas de la familia: Correo Argentino, Autopistas del Sol, la constructora Sideco y Socma; participó además en la gestión del club de fútbol Boca Juniors cuando Macri fue su Presidente.

Señalado como el gran "gerente de recursos humanos del Estado", el periodismo solía destacar su cercanía y vínculo de confianza con el presidente Macri, luego de años de trabajo en conjunto. Ser amigo del Presidente resultaba el título más ostensible de la legitimidad del candidato que dirigiría el proceso de modernización de la administración pública y la razón de su nombramiento en esa posición. Desde la mirada de un funcionario de alto rango que lo acompañó en la gestión en CABA y luego en el MMN, el ministro no representaba un perfil netamente político, sino 
proyectaba la contraimagen del político tradicional: "Andrés cero con la política. No tiene interés en hacer carrera política" ${ }^{17}$.

Ahora bien, si nos enfocamos en la composición del MMN, encontramos en primer lugar que su funcionariado era predominantemente masculino: casi el $60 \%$ de sus miembros eran hombres. Esta era una característica que compartía con el gabinete nacional en su conjunto, según lo demostraban estudios que analizaron a los miembros de todos los ministerios del gobierno de Cambiemos, hasta el rango de subsecretaría (Canelo y Castellani 2016a, 2016b). Aunque la composición por género era casi pareja en el último estrato contemplado en nuestra muestra (el cargo de Coordinador/a), la distribución se hacía más asimétrica a favor de los hombres a medida que se ascendía en la escala jerárquica del MMN. En el nivel máximo, en el que se concentraba la toma de decisiones, el 73,7\% eran hombres.

En segundo lugar, se trataba de una plantilla de funcionarios relativamente joven. La edad promedio era 44 años. Este rasgo no desentonaba con la composición etaria general de funcionariado del gobierno de Cambiemos (con un promedio de edad de 50 años), según arroja el análisis completo del gabinete inicial que abarcó hasta el rango de subsecretarías (Canelo y Castellani 2016a, 2016b).

Además, el conjunto de funcionarios del MMN mostraba un nivel educativo alto: el $86,8 \%$ contaba con un título de grado y el $43,9 \%$ poseía un diploma de posgrado. En el segmento de los directores nacionales o generales esta característica era aún más pronunciada: 9 de cada 10 funcionarios de este rango tenían al menos un diploma de grado $(91,9 \%)$ y 6 de cada 10 uno de posgrado (60\%). Ciertas dependencias concentraban más personal que había accedido a una formación de posgrado que el promedio general de la cartera, posiblemente esto estuviera relacionado con la materia de la que se ocupaban y el nivel de actualización de conocimientos requerido en el área. La Secretaría de Tecnologías de la Información y las Comunicaciones (STIC) y la Subsecretaría de Innovación Pública y Gobierno Abierto (SSIPGA) mostraban un 70\% y un 66,7\% de graduados de posgrado, respectivamente.

En el universo de funcionarios del MMN, como era esperable, los títulos de grado de las disciplinas tradicionales se encontraban bien representados: el $21,1 \%$ del personal analizado del MMN estaba titulado en Derecho, $11,3 \%$ en Contabilidad y 9,2\% en Ingeniería. Sin embargo, se destacaban también los títulos en Ciencia Política y Relaciones Internacionales

17 Entrevista con funcionario del área de Relaciones Institucionales, realizada el 14 de agosto de 2018. 
(16,2\%), Administración de Empresas (11,3\%) y Sistemas (9,9\%). Los diplomas expedidos por la Universidad pública (predominantemente la UBA) se encontraban más representados que los de las instituciones privadas: en la base que construimos del MMN, el 61,8\% de los graduados provenía de universidades públicas, el 25,2\% de universidades privadas laicas y $13 \%$ de confesionales ${ }^{18}$. La proporción de funcionarios egresados de las universidades públicas era muy semejante, aunque algo inferior, a la que mostraba la población universitaria argentina en general que, según datos de 2016, constituía un 66\% (Ministerio de Educación sin fecha, 2018).

Vale la pena mencionar que tanto el ministro como aquellos secretarios y subsecretarios que contaban con estudios de grado en instituciones privadas se recibieron exclusivamente en universidades confesionales (UCA y Usal). Si bien el paso por estas instituciones religiosas no se traduce mecánicamente en una identidad social e ideológica dada, la actualización de los vínculos allí entablados es indicativa de mundos sociales de pertenencia en los cuales el PRO -y por ende los cuadros políticos del MMN- abrevaba a la hora de movilizar referentes, actores, ideas y repertorios de acción (Vommaro 2015, 2016).

Si el abanico de disciplinas presente en el MMN era bastante amplio a nivel de los estudios de grado, advertimos una mayor concentración en el nivel de posgrado y la prevalencia de carreras vinculadas a la gestión privada o pública. Más de la mitad de quienes tenían un título de posgrado eligieron administración de empresas o administración y políticas públicas. De hecho, el 34,3\% y el 26,9\%, respectivamente, poseía un diploma de posgrado en esas disciplinas. Le seguían las especializaciones en derecho $(10,4 \%)$, relaciones del trabajo o recursos humanos $(10,4 \%)$ y economía y finanzas (9\%). La distribución de los tipos de posgrados no era homogénea entre las jerarquías, de manera tal que era posible advertir que: los titulados en Economía y Finanzas tenían más relevancia en la cúspide de la estructura del MMN, mientras que el peso de diplomas de posgrado en administración y políticas públicas tendía a aumentar en la medida que se descendía en los niveles jerárquicos. Las personas con diplomas de posgrado en administración de empresas estaban bastante concentradas en el rango de directores nacionales o generales (70\%). En el rango de

18 Otros estudios han señalado la singular relevancia que asumió la enseñanza privada en las carreras de grado de los funcionarios de la administración Cambiemos. El análisis de una de muestra de 104 funcionarios que se desempeñaban en áreas económicas y afines, que tomaba en consideración desde el rango de subsecretaría en adelante, arrojó resultados similares (FLACSO-CIFRA/CTA 2016). En línea con lo observado aquí para el $\mathrm{MMN}$, ese trabajo también indica que en la instancia de posgrado se invierte la importancia de las instituciones educativas públicas y privadas. 
las coordinaciones, sin embargo, la mitad de los funcionarios tenía un posgrado en Administración y Políticas Públicas.

Es importante destacar que 3 de cada 10 funcionarios del MMN con título de posgrado $(32,4 \%)$ habían obtenido su diploma en una universidad extranjera. En el caso de los posgrados nacionales, las universidades privadas - las laicas $(30,9 \%)$ aún más que las confesionales (23,5\%)- adoptaban un peso mayor que las públicas $(18,5 \%)$, inversamente a lo observado para la formación de grado. En la elección de los estudios de posgrado, la mayor inclinación por las universidades privadas (antes que las públicas) se evidenciaba en todos los rangos jerárquicos analizados, desde la categoría de Ministro y secretarios/as a la de coordinadores/as. Si consideramos al posgrado como el último escalón de la formación, en el que se consolidan los conocimientos técnicos especializados, pero también las relaciones tanto institucionales como sociales (sea en el medio local o en el extranjero), y se refuerzan las identidades ideológicas (FLACSO-CIFRA/CTA 2016: 13), la preferencia por las universidades privadas resulta significativa porque nos acerca al universo social en el que se mueven estos funcionarios y la cosmovisión adquirida a través de esa experiencia.

Resulta infructuoso evaluar la pertinencia de la formación universitaria del cuerpo de funcionarios del MMN, o la adecuación a su función, en tanto, como sostuvimos más arriba, no existía un quehacer de la modernización estatal establecido de antemano, por lo que tampoco estaban definidas con antelación las competencias necesarias para llevar a cabo la tarea, sobre todo teniendo en cuenta la ausencia de una historia previa de prácticas modernizadoras que hubieran sedimentado en roles específicos. Al mismo tiempo, desde una perspectiva sociopolítica, son las prácticas las que hacen a la institución, por tanto, era de esperar que fuera esta primera generación de funcionarios -autoidentificados como los verdaderos modernizadoresquienes dieran los pasos iniciales en cuanto a delinear el perfil modelo del especialista en modernizar el Estado.

Estudios recientes han llamado la atención acerca de la presencia e influencia de los CEOs en el gabinete de Macri (Canelo y Castellani 2016a, 2016b). Esta literatura aportó la noción de puerta giratoria para hacer referencia a la participación de empresarios en el gobierno de Cambiemos bajo la hipótesis de que estos buscaron incidir en el accionar del Estado en favor de los sectores, las empresas o los nichos de negocios de los que procedían. En nuestra investigación pudimos constatar que 14 funcionarios del MMN se desempeñaron en empresas pertenecientes al Grupo Macri (tales como Sideco o Sevel) o vinculadas al Presidente. Casi todos ellos ocuparon posiciones de alta jerarquía en el MMN. 
Pero, si el MMN se ajusta, en parte, a esa descripción del sesgo gerencialista del gobierno de Macri teniendo en cuenta exclusivamente a quienes se ubican en la cima de su estructura, estaba habitado también por un conjunto más amplio y heterogéneo de funcionarios que lo convertían en un entramado administrativo mucho más complejo. Por un lado, tres cuartas partes del funcionariado del MMN (78,5\%) contaba con experiencia en el sector público estatal, es decir, no se trataba de advenedizos. Algunas de las dependencias, sobre todo las orientadas a la administración de los recursos humanos del Estado, que eran más bien populosas, mostraban una alta concentración de personal experimentado en el sector estatal, con trayectorias mínimas promedio de entre 14 y 8 ańos. La extensión de su experiencia en el sector público estatal los hacía individuos proclives a generar cierto sentido de pertenencia y un interés por el Estado y, en el sentido que le da el sociólogo Pierre Bourdieu (2014), a convertirse en partidarios del Estado.

Por otro lado, un $27,3 \%$ de los funcionarios se desempeñaba en el sector privado como trabajo previo a su ingreso al MMN. A su vez, dos terceras partes del funcionariado de este ministerio (67,6\%) desempeñaban un cargo en el sector público estatal al momento de su designación. Tal como se advierte en el Gráfico 1, el momento de creación del MMN fue cuando se produjeron más traslados de funcionarios del sector privado al público. No obstante, este pasaje se fue desarrollando de manera más bien progresiva, por oleadas de magnitud creciente. Sobre el total de 90 funcionarios cuya trayectoria profesional se inició en el sector privado y luego continuó en el sector público estatal, un 5,6\% dio el salto -tomando prestada la expresión del sociólogo Gabriel Vommaro (2017) - al sector público estatal antes de 2007, un 16,7\% entre 2007 y 2011 -durante el primer gobierno de Mauricio Macri en la Ciudad de Buenos Aires-, un $31,1 \%$ entre 2012 y 2015 -período en el que se puso en marcha el Ministerio de Modernización porteño- y un 46,7\% a partir de 2016 -con la llegada de Cambiemos a la Casa Rosada.

En los niveles jerárquicos más altos. en los que se concentra, en última instancia, la toma de decisiones (autoridad ministerial, secretarías y subsecretarías), la proporción de funcionarios que provenía de otro cargo en el sector público estatal ascendía al 78,9\%. Sin embargo, las direcciones nacionales, generales o simples parecen haber sido las más ofrecidas a quienes se desempeñaban hasta hacía poco tiempo en el sector privado (dado que allí observamos las proporciones más altas de funcionarios que venían del sector privado, con un 27\% y 33,3\%, respectivamente) y decidieron "dar el salto" (Vommaro 2017). Existían dependencias del MMN donde el ejercicio inmediato anterior de funciones en el sector 
privado tenía un mayor peso relativo: en la Subsecretaría de Gobierno Digital, por ejemplo, más de la mitad de los funcionarios $(58,8 \%)$ procedía del sector privado. Mientras tanto, otras dependencias estaban formadas casi por completo por personal que venía desempeñándose en el sector estatal $^{19}$. Es decir, contemplado en su conjunto, el MMN parecía ser un cuerpo burocrático heterogéneo, de perfiles de funcionarios disímiles con procedencias variadas, por lo que cabe suponer que construyeron intereses y lealtades también diversas.

\section{Gráfico 1: Ingresos al sector público estatal del funcionariado del MMN, según período}

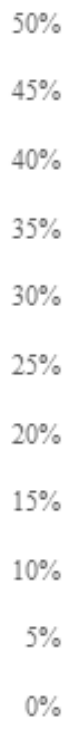

$45 \%$

$40 \%$

$35 \%$

$30 \%$

$25 \%$

$20 \%$

$10 \%$

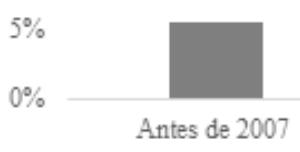

Nota: Solo se contemplan aquellos funcionarios cuta trayectoria profesional se inició en el sector privado y luego continuó en el sector público estatal

Fuente: Elaboración propia.

Como era de esperar, las dependencias estatales que actuaron como los afluentes principales de personal a la nueva cartera fueron el Ministerio de Modernización de CABA $(26,1 \%)^{20}$, las Jefaturas de Gabinete nacional

19 Nos referimos a la Subsecretaria de Relaciones Laborales y Fortalecimiento del Servicio Civil (SSRLFSC), la SSIPGA y la Subsecretaría de Coordinación Administrativa (SSCA) con $100 \%, 81,8 \%$ y $76,9 \%$, respectivamente.

20 Quienes provenían del ex Ministerio de Modernización porteño se distribuyeron horizontalmente en casi todas las dependencias, aunque en proporciones desiguales. Las principales receptoras de estos funcionarios fueron la SSCA y la Secretaría de Innovación Tecnológica y País Digital (SITPD). 
$(9,1 \%)^{21}$ y porteña $(4 \%)$-donde existían programas de modernización estatal antes de 2015-, junto al Ministerio de Hacienda también del gobierno local $(4,5 \%)^{22}$. Al contemplar la distribución del personal con un cargo en la gestión pública al momento de ingresar a la nueva cartera, constatamos que cuanto más alta la jerarquía, mayor era el peso de los antecedentes en el gobierno porteño (sobre todo en el Ministerio de Modernización local). Es posible plantear como hipótesis que los funcionarios más altos se movieron de una jurisdicción a otra en una misma área, pasando de la administración porteña a la administración nacional con la asunción de Macri como Presidente. No obstante, fueron el segmento más afectado por los cambios de organigrama -debido a la absorción de estructuras del gobierno anterior o a cambios en las nuevas estructuras del ministerio- $y$ que, por lo tanto, acumuló más cargos de corta duración en el gobierno nacional (el $21,1 \%$ ocupó dos o más cargos).

Es necesario subrayar que todas las dependencias del MMN tenían como piso un $50 \%$ de su personal con alguna experiencia en el sector público estatal. Incluso encontramos en el MMN un 28,3\% de funcionarios de perfil público estatal puro ${ }^{23}$, es decir, que en su trayectoria laboral solo habían circulado al interior de la estructura de la administración pública. Pero las jerarquías más altas eran un poco más experimentadas que las más bajas (mientras que la mitad de quienes ocuparon los cargos en secretarías y subsecretarías mostraba una trayectoria mínima en el sector público estatal de 8 años, en las direcciones simples y coordinaciones la mediana era de cuatro años).

Por otra parte, analizamos la experiencia de los funcionarios del MMN tomando en consideración el momento de ingreso al sector público estatal y agrupando los años de acuerdo a los períodos de gobierno. En este aspecto observamos que los funcionarios del MMN se distribuían de manera bastante homogénea: un 28,7\% había ingresado al Estado de la mano del gobierno nacional de Cambiemos (entre 2016 y 2018), un

21 Advertimos que aquellos que contaban con un cargo en la Jefatura de Gabinete nacional al momento de su designación se encontraron en la Secretaría de Empleo Público (SEP, con el 18.8\%), la Secretaría de Modernización Administrativa (10,5\%) y, principalmente en la SRLFSC, donde más de la mitad de sus integrantes provino de la JGM nacional.

22 La mayoría de los antiguos integrantes de la Jefatura de Gabinete de la CABA confluyeron en la Secretaría de Modernización Administrativa, donde conformaban el 13,2\% del personal. Aquellos provenientes del Ministerio de Hacienda de la CABA se distribuyeron entre la SEP, la SSCA y la Secretaría de Modernización Administrativa.

23 Se trata de funcionarios que solo se desempeñaron en la administración pública y que, por lo tanto, no acumularon cargos significativos en el sector privado, en organizaciones de la sociedad civil o en organismos supranacionales. 
$23,8 \%$ entre 2012 y 2015 , un $21 \%$ entre 2007 y 2011 , y un $26,6 \%$ antes del 2007. Teniendo en cuenta que el ingreso a la administración pública pudo haberse dado en las distintas jurisdicciones de gobierno (nacional, provincial o municipal), es interesante remarcar que casi un cuarto de estos funcionarios ingresó al sector público estatal a partir de 2012, periodo en el que se puso en marcha el Ministerio de Modernización en CABA. Al mismo tiempo, sabemos que un 37,4\% de los funcionarios del MMN alguna vez ocupó un cargo en el Ministerio de Modernización porteño y, como ya se mencionó, más de un cuarto se desempeñaba allí inmediatamente antes de ingresar al MMN. Por tanto, este ministerio fue una de las expresiones más cabales del trasplante de equipos que operó Cambiemos a la hora de acceder al Poder Ejecutivo Nacional en 2015 (Canelo y Castellani 2016b: 31). En el caso específico del MMN, el traslado fue más pronunciado en los niveles jerárquicos más altos y en ciertas dependencias en particular, como la SITPD, la SSCA y la SSIPGA.

A pesar de ser una creación institucional de Macri, el 21,3\% de los integrantes del MMN trabajaba en el Estado desde la gestión kirchnerista previa a la de Cambiemos. Esta proporción da cuenta de la continuidad que el MMN supone en muchos aspectos, en sentido contrario a la retórica rupturista que se eligió oficialmente para presentarlo. La proporción de funcionarios que provenían de la gestión anterior disminuía, lógicamente, al ascender en los niveles jerárquicos (ninguno de los/as secretarios/as o subsecretarios/as venía de la gestión anterior, pero sí un tercio de los/as coordinadores/as). Las dependencias con mayor proporción de funcionarios que continuaban de la gestión anterior eran la Subsecretaría de Relaciones Laborales y Fortalecimiento del Servicio Civil, con el 62,5\%, y la SEP, con el 38,7\%. Por el contrario, existían dependencias sin funcionarios provenientes de la gestión anterior, como la Subsecretaría de País Digital y Gobierno Abierto, la Dirección Nacional de Relaciones Institucionales y la Unidad de Auditoria Interna. Es decir, en determinadas zonas del MMN la gestión Cambiemos mantuvo un alto nivel de discrecionalidad política en la contratación. Este tipo de discrecionalidad se mostró también en la creación de dependencias pequeñas, en cuanto a su cantidad de personal, pero compuestas por personas de extrema confianza, donde colocar acólitos. Combinado con modalidades flexibles de contratación, la lógica discrecional suele tener un efecto doblemente negativo: por un lado, contribuye a la formación de un cuerpo de funcionarios altamente vinculado a la gestión política, donde lo que impera al momento de la selección del personal no es necesariamente su capacidad técnica; por otro lado, este rasgo da como resultado una alta volatilidad de elencos que se desmantelan completamente ante cada cambio de gestión. 
La abrumadora mayoría del personal del MMN que conforma nuestra muestra no pertenecía a la planta permanente (representando el 95,1\%) ${ }^{24}$. La precariedad de esta situación laboral -empleados que no cuentan con estabilidad en sus puestos y se encuentran por fuera de cualquier esquema de promoción- estaba tan extendida que no discriminaba por nivel jerárquico. Pudimos identificar que casi la totalidad de los funcionarios del MMN con estabilidad en la relación laboral, por su pertenencia a planta permanente, se concentraba en solo dos dependencias del MMN: las mencionadas SEP y SSRLFSC, las mismas que contenían a los funcionarios más experimentados en el sector público. En este aspecto, la gestión Cambiemos no ha revertido formas de contratación vigentes en la administración pública que eran objeto de preocupación de sus líderes políticos, incluso en el MMN, la dependencia que tenía entre sus fines velar por la calidad y profesionalización del empleo público.

Finalmente, la información acerca de los perfiles de los funcionarios del MMN aquí analizada nos habilitó un acercamiento general a los criterios de selección y los principios valorativos que actuaron -tácita o explícitamenteen la configuración del plantel del MMN. En este sentido, además de la inclinación por incorporar cuadros jóvenes, detentar una formación en la gestión pública no apareció como una exigencia al perfil reclutado. La cercanía política y la confianza gravitaron claramente en la conformación (y el cierre) de las altas cumbres del ministerio. Aunque se promocionó como el gobierno de los equipos técnicos, la alianza Cambiemos no innovó ni se apartó de la conducta de los partidos políticos tradicionales cuando acceden a manejar las estructuras del Estado. Constatamos que ningún funcionario de alta jerarquía de la nueva cartera provenía de la gestión anterior del gobierno nacional, como era de esperarse, pero además que los lazos de confianza fueron muy valorados a este nivel. Podemos decir que se ha puesto en evidencia la tensión existente entre los principios de autoridad invocados al hablar públicamente del funcionariado que acompañaba al presidente Macri como el "mejor equipo de los últimos 50 años”-el mérito, la experiencia y las competencias específicas-, y la lógica casi familiar revelada más tarde, donde lo realmente valorado fue la fidelidad y la dependencia personal respecto del líder. Parafraseando al sociólogo Pierre Bourdieu, no se trata de otra cosa que las contradicciones constitutivas del trabajo de dominación política (Bourdieu 2014: 358).

24 Este dato contrasta con la tendencia general de la región hacia la profesionalización de la Alta Dirección Pública, donde la selección por concurso y la perdurabilidad en los cargos son herramientas clave. Ver, por ejemplo, Ramos y Scrollini (2013). 
La politización, entendida como discrecionalidad en el nombramiento de funcionarios, guiado por afinidades ideológicas y partidarias antes que, por su probidad para el cargo, no se opone necesariamente al ideal de un cuerpo de administradores profesionales (es decir, puede existir una burocracia politizada y profesional, a la vez, y esas zonas grises abundan). Sin embargo, la politización pone en riesgo su continuidad en el largo plazo. La débil institucionalización de los sistemas burocráticos de carrera en la Argentina no es una cualidad exclusiva del gobierno de Cambiemos. Lo que sí llama la atención es que la creación del MMN tuvo por objeto explícito romper con esa tendencia, sin lograrlo.

\section{REFLEXIONES FINALES}

En este artículo mostramos que, tanto en sus objetivos como en la terminología utilizada, la propuesta de modernización del Estado que encarnó el MMN se inscribía en una línea de diagnóstico y proyectos que llevaba al menos 15 ańos en la Argentina. Poner sobre relieve estos antecedentes no significa invalidar la habilidad política que demostró el gobierno de Cambiemos para instalar en la esfera pública la idea de que la modernización del Estado era un imperativo ineludible. La retórica de innovación que esgrimieron los partidarios de esta "nueva" modernización chocaba, sin embargo, con las continuidades que pusimos en evidencia tanto en el plano del tipo de metas y acciones consideradas apropiadas para transformar al Estado, como en la prolongación de áreas preexistentes (y la continuidad de los funcionarios allí presentes). Ahora bien, si volcamos la mirada en la gestión que le sucedió a Macri en diciembre de 2019, de signo ideológico opuesto, encabezada por el presidente Alberto Fernández, identificamos también indicios de continuidad y pervivencia de, al menos, un discurso común con el de su antecesor en materia de modernización estatal, que indicaría lo transversal a la dirigencia política argentina que se ha configurado la agenda modernizadora con el correr del tiempo.

Respecto a la gestión Cambiemos, en este trabajo fundamentamos que la experiencia de dar vida al MMN consistió, en buena medida, en un trasplante: el deslizamiento entre las jurisdicciones de ciudad y Nación se puso de manifiesto en el contenido de la agenda modernizadora, en las estructuras o formas de organización y en la conducción política y técnica del plantel de funcionarios. En el paisaje burocrático del gabinete inicial del presidente Macri, el MMN se destacó por la centralidad que adquirió en la esfera pública y por la transversalidad de las funciones que se le encomendaron; estos rasgos lo llevaron a insertarse en una trama de tensiones hacia adentro, al interior del propio gobierno, y hacia afuera, en el campo más amplio de la comunicación política. Identificamos, además, 
que la corta vida institucional del MMN tuvo dos etapas: una primera de expansión institucional y de concentración de recursos, y un segundo momento de aparente repliegue, marcado por la pérdida de la jerarquía ministerial. Pero, señalamos también que este cambio de denominación tuvo un carácter formal y no alteró el peso presupuestario del área al interior de la administración macrista, ni significó retroceso alguno o pérdida de respaldo político para la empresa modernizadora.

Por otra parte, este trabajo dio cuenta de la importancia que las relaciones personales tuvieron en la gestión Cambiemos. La confianza resultó central al momento del reclutamiento y armado del plantel que llevaría adelante la modernización del Estado nacional a partir de 2015. Aunque el proyecto modernizador se presentaba como disruptor de lógicas enquistadas en el Estado argentino, demostramos que el propio MMN no escapó a la politización de los cargos públicos.

En retrospectiva, el recorrido que hizo el MMN durante los años de gobierno de Cambiemos mostró una trayectoria paradojal ya que, como su antecesor en CABA, terminó siendo víctima de su propio discurso modernizador. Nacidos al calor de la agenda de la alianza gobernante enfocada en alcanzar el equilibrio fiscal vía recorte presupuestario, con el objetivo puesto en el empleo público como causa del despilfarro estatal, ambos organismos perdieron estatus dentro de sus respectivas jurisdicciones con una justificación basada, precisamente, en la necesidad de reducción del gasto público. Aunque la reducción del volumen del empleo público fue una de las misiones manifiestas del MMN, perseguida mediante un programa de evaluación y planificación de dotaciones, en este trabajo subrayamos que esas acciones no redundaron en una disminución significativa del empleo público, sino que implicaron una descentralización y una reducción de los cargos de ADP que la misma gestión macrista había generado.

Mediante el análisis de las tareas, la estructura y el perfil social de los funcionarios del MMN, pudimos confirmar la persistencia de lógicas previas ya inscriptas en el Estado: por un lado, en cuanto a las formas de reclutamiento y de selección, detectamos altos márgenes de discrecionalidad política y la preeminencia de factores como la cercanía política y la confianza en el nombramiento de funcionarios. Sostenemos que esta primacía de los vínculos personales y de la identificación ideológica al momento de la contratación coartó en alguna medida las posibilidades de que aquella primera generación sentara las bases de lo que podría, a partir de entonces, ser considerado como un perfil ideal para quien se dedicara a la modernización del Estado, en tanto no fueron 
sus calificaciones específicas las que habilitaron al usufructo del cargo, sino sus vínculos. Con relación a los tipos de contratación, la gestión Cambiemos no revirtió formas ya vigentes en la administración pública que eran criticadas por sus líderes políticos antes de acceder al gobierno, las modalidades flexibles de contratación persistieron y la precariedad laboral fue una característica distintiva incluso del MMN. Por último, el MMN mostró escasos resultados en cuanto a su propuesta de consolidación de un servicio civil de carrera.

Por otro lado, consideramos que la propia composición heterogénea del MMN (la diversidad de perfiles y procedencias de sus funcionarios que constatamos en este trabajo), sumado a sus complejidades intrínsecas, afectó los logros alcanzados en la dimensión cultural de la modernización. Hacemos referencia a que, aunque estaba claro que los responsables políticos del MMN comulgaban con los valores centrales de la nueva gerencia pública, la presencia y vocación de esos líderes del cambio no alcanzaron para garantizar la interiorización en la administración pública nacional de los principios de la cultura organizacional managerialista que el gobierno quiso imprimirle al Estado, promoviendo el agilismo, el mérito y la competencia.

Aunque encontramos similitudes entre los objetivos de Macri en materia de modernización y la gestión presidencial que asumió recientemente, resulta claro que la agenda de modernización estatal ocupa en esta primera mitad de 2020 un lugar, en principio, menos protagónico, más alejado del centro de la escena pública. Buena parte de las responsabilidades que asumió el MMN siguen vigentes bajo la órbita de la Jefatura de Gabinete de Ministros, especialmente en la Secretaría de Gestión y Empleo Público. Allí perviven, al menos discursivamente, nociones como transparencia e integridad; herramientas como la gestión por resultados y la evaluación de desempeño; los propósitos de jerarquización y capacitación del empleo público. De la misma manera, en estos pocos meses de gestión se mantuvo la adhesión a estándares y rankings internacionales (Jegatura de Gabinete de Ministros). Es decir, continúa la injerencia de cierto encuadre promovido por organizaciones internacionales que queda exento de cuestionamientos o de problematización, tal como en la gestión anterior. Los estándares internacionales se asumen nuevamente como un destino ineludible. Se trata de una cosmovisión transversal a la dirigencia política nacional, ya que existen indicios de su aceptación generalizada.

Sin embargo, mientras que el presidente Fernández consideró apropiado reponer como ministerios ciertas carteras (como Salud, Educación y Ciencia) que habían perdido su estatus tras la resolución de 2018, no fue 
así con Modernización. Podemos preguntarnos si la falta de una demanda social específica de modernización estatal no opera como un desincentivo para la recuperación de un lugar dentro del gabinete o si la escasa visibilidad pública de los impactos de la tarea modernizadora conlleva un bajo rédito político y, por tanto, actúa en el mismo sentido. Otra interpretación puede tejerse siguiendo la huella de una de las hipótesis propuestas por este trabajo, que señala que, en la Argentina, los procesos de modernización fueron altamente dependientes de ciertas figuras que los encarnaron y les dieron forma.

La situación originada por la pandemia de Covid-19 a poco de iniciarse el mandato del presidente Fernández puso a prueba la modernización del Estado. Si bien la urgencia sanitaria acaparó los debates, también visibilizó, como solo lo hacen las situaciones críticas, las dificultades que continúan sin resolverse. La extensión de la conectividad a Internet a nivel federal, misión que el MMN se había atribuido como objetivo central, se reveló insuficiente; mientras que el trabajo a distancia que realiza buena parte de las/os empleadas/os públicos durante la pandemia es posible gracias a los sistemas de Gestión Documental Electrónica y otras herramientas, como la firma digital, que actualizó y/o desarrolló el $\mathrm{MMN}^{25}$. Pero las situaciones críticas también marcan el límite de lo que los sistemas informatizados pueden ofrecer, y resolver por sí solos, en el escenario de una situación extrema. En medio de la pandemia, justamente cuando la urgencia marca la necesidad de acciones resolutivas y de inmediatez en la trasmisión de información, fallas de seguridad (intencionalmente causadas o no) en el sistema de firma digital (iProUP 2020) y caídas del sistema que demoraron comunicaciones oficiales llevaron al presidente Fernández a firmar un decreto que autoriza la vuelta al papel para los actos administrativos o comunicaciones. Toda una paradoja de la modernización estatal.

25 El Sistema de Gestión Documental Electrónica fue creado por decreto presidencial $\mathrm{N}^{\circ} 561$ en abril de 2016, a poco de iniciado el gobierno de Macri. 


\section{REFERENCIAS}

Asinelli, Ch. Álvarez Travieso, M. y Yodert, P. (2008). El proceso de modernización del Estado en la Argentina: Características y particularidades de un pensamiento propio e innovador. Cuadernos de Administración, 39, 83-95.

ATE, CTA, CLATE, IDEPA. (2016). Repensando el Estado en el siglo XXI. Debates y propuestas para un Estado Democrático y Popular. Ira, 2da y 3 ra jornada. Buenos Aires: ATE - CTA - CLATE - IDEPA. Disponible en http://ate.org.ar/img/pdf/pub/tapa-1.pdf, http://ate.org.ar/img/ pdf/pub/tapa-2.pdf y http://ate.org.ar/img/pdf/pub/tapa-3.pdf [2706-2020].

Barros, S., Castellani, A. y Gantus, D. (2016). Estudios sobre estado, gobierno y administración pública en la Argentina contemporánea. Ciudad Autónoma de Buenos Aires: CLACSO.

Bernazza, C. (2016). Bienvenidos al pasado. Revista Perspectivas de Políticas Públicas, 11, 23-37.

Blutman, G. (2009). La reforma y modernización del estado en Argentina, el papel de la cultura organizacional. Buenos Aires: Universidad de Buenos Aires, Facultad de Ciencias Económicas.

. (2013). Ensayos truncos de reforma y modernización del Estado en Argentina. En Madureira, C. y Asensio, M. (Orgs.), Handbook em Administração Pública. Lisboa: Ina Editora.

Bourdieu, P. (2014). Sobre el Estado. Madrid: Anagrama.

Buonfiglio, Y. (2016). Los nombres del cambio: apuntes para una cartografía del discurso político en la Argentina PRO. Raigal, Revista Interdisciplinaria de Ciencias Sociales, 2, 39-51.

Canelo, P. y Castellani, A. (2016a). Empresarios en el Estado. Radiografía del gabinete nacional (Documento de Trabajo). Buenos Aires: Observatorio de las Elites, CITRA/UMET. Disponible en https:/citra.org.ar/ wp-content/uploads/2020/01/2016_Empresarios_en_el_Estado_ Observatorio_de_las_Elites.pdf [27-06-2020].

Canelo, P. y Castellani, A. (2016b). Perfil sociológico de los miembros del gabinete inicial del presidente Mauricio Macri (Informe de Investigación 
$\mathrm{N}^{\circ} 1$ ). Buenos Aires: Observatorio de las Elites Argentinas, IDAES, UNSAM.

Centro de Implementación de Políticas Públicas para la Equidad y el Crecimiento (CIPPEC) (sin fecha). CIPPEC participará en la implementación del Compromiso Federal de Modernización. Disponible en https://www.cippec.org/cippec-participara-en-la-implementaciondel-compromiso-federal-de-modernizacion/ [11-05-2019].

Compromiso Federal para la Modernización del Estado. (2017). Disponible en: https://www.argentina.gob.ar/sites/default/files/compromiso_ federal_para_la_modernizacion_del_estado_0.pdf [16-05-2019].

Coutinho, M. E. (2016). Directivos públicos-Funcionarios Políticos. Una Relación Débilmente Institucionalizada. En CIPPEC y ASAP (Eds.), GPS del Estado. Buenos Aires: CIPPEC y ASAP. Disponible en https:// www.cippec.org/wp-content/uploads/2017/03/1122.pdf [11-052019].

Estévez, A. (Comp.) (2001). La reforma managerialista del Estado: nueva gerencia pública, calidad total y tecnocracia. Buenos Aires: Ediciones cooperativas.

. (2003). El nuevo management público después de la Reforma del Estado Argentina (Documento de Trabajo). Buenos Aires: Polipub Políticas Públicas Participativas para el mejoramiento de la calidad democrática. Disponible en https://panel.inkuba.com/sites/2/ archivos/EL\%20NMP\%20luego\%20de\%20la\%20reforma\%20 argentina\%202003.pdf [11-05-2019].

Etchemendy, S. (2018, 17 de septiembre). El asalto a las capacidades estatales PRO: el desmanejo administrativo contra el Estado de Bienestar y el desarrollo. Artepolítica.com. Disponible en http://artepolitica. com/articulos/el-asalto-a-las-capacidades-estatales-pro-el-desmanejoadministrativo-contra-el-estado-de-bienestar-y-el-desarrollo/ [16-052019].

FLACSO, CIFRA/CTA. (2016). La naturaleza política y económica de la alianza Cambiemos (Documento de Trabajo No 15). Buenos Aires: FLACSO, CIFRA/CTA. Disponible en http://www.centrocifra.org. ar/docs/DT\%2015.pdf [27-06-2020]. 
Gaetani, F. (2000). La intrigante reforma administrativa brasilera. Revista del CLAD, Reforma y Democracia, 16, 1-14.

García Delgado, D. (2017). Modernización y reforma del Estado en el neoliberalismo tardío (Documento de Coyuntura No3). Buenos Aires: Área Estado y Políticas Públicas, FLACSO Argentina.

García Delgado, D. y Gardin, A. (Comps.) (2017). El neoliberalismo tardio. Teoría y praxis (Documento de Trabajo N5). Buenos Aires: Área Estado y Políticas Públicas, FLACSO Argentina.

Gasparin, J. y Diéguez, G. (2018). GPS del Estado: radiografía 2017/2018 (Documento de Políticas Públicas №206). Buenos Aires: CIPPEC. Disponible en https://www.cippec.org/publicacion/gps-del-estadoradiografia-2017-2018/ [11-05-2019].

González-Bustamante, B., Olivares L. A., Abarca, P. y Molina, E. (2016). Servicio civil en Chile, análisis de los directivos de primer nivel jerárquico (2003-13). Revista de Administaçao Pública, 50 (1), 59-80.

Iacoviello, M., Llano, M. y Ramos, C. (2017). Alta Dirección Pública Latinoamericana: Marchas Y Contramarchas. Revista de Gestión Pública, 6 (2), 173-214.

iProUP. (2020). ¿Vuelve el papel?: Alberto Fernández acusó que su firma digital fue "hackeada". Disponible en https://www.iproup.com/ innovacion/12941-alberto-fernndez-asegura-que-su-firma-digital-fuehackeada [16-06-2020].

Jefatura de Gabinete de Ministros. (sin fecha). Tablero Ciudadano. Argentina. Disponible en https:/www.argentina.gob.ar/tablerociudadano [11-05-2019].

. (2020). El gobierno avanza en la transparencia y el acceso a la información. Argentina. Disponible en https://www.argentina. gob.ar/noticias/el-gobierno-avanza-en-la-transparencia-y-el-acceso-lainformacion [27-06-2020].

López, A. (2005). Los fundamentos de la nueva gestión pública: lógica privada y poder tecnocrático en el Estado mínimo. En Thwaites Rey, M y López, A. (Comps.), Entre tecnócratas globalizados y politicos clientelistas. Buenos Aires: Prometeo. 
Ministerio de Educación. (sin fecha). Estadísticas Universitarias. Disponible en http://estadisticasuniversitarias.me.gov.ar/\#/seccion/1 [27-062020.]

. (2018). Sintesis de información universitaria 20172018. Disponible en https:/www.argentina.gob.ar/sites/default/files/ sintesis_2016-2017.pdf [27-06-2020].

Ministerio de Hacienda. (2016). Presupuesto del Ministerio de Modernización de la Nación, año 2016. Disponible en https://www.minhacienda.gob. ar/onp/documentos/presutexto/ley2016/jurent/docs/D16J26.rtf [2706-2020].

. (2017a). Presupuesto del Ministerio de Modernización de la Nación, año 2017. Disponible en https:/www.minhacienda.gob.ar/ onp/documentos/presutexto/ley2016/jurent/docs/D16J26.rtf [27-062020].

. (2017b). Presupuesto Nacional 2017. Planillas Anexas Administración Central. Disponible en https://www.minhacienda.gob. ar/onp/presupuestos/2017 [27-06-2020].

(2018a). Presupuesto del Ministerio de Modernización de la Nación, año 2018. Disponible en https:/www.minhacienda.gob.ar/ onp/documentos/presutexto/ley2018/jurent/docs/D18J26.rtf [27-062020].

.. (2018b). Presupuesto Nacional 2018. Planillas Anexas Administración Central. Disponible en https://www.minhacienda.gob. ar/onp/presupuestos/2018 [27-06-2020].

. (2019). Presupuesto Nacional 2019. Planillas Anexas Administración Central. Disponible en https://www.minhacienda.gob. ar/onp/presupuestos/2019 [27-06-2020].

Ministerio de Modernización, Subsecretaría de Innovación Pública y Gobierno Abierto. (2017). Kit de evaluación. Herramientas para una gestión ágil: Teoría de Cambio y pensamiento evaluativo. Disponible en https://www.argentina.gob.ar/sites/default/files/6._kit_de_ evaluacion_-_herramientas_para_gestion_agil.pdf [11-05-2019]. 
Pardo, M. C. (2010). La propuesta de modernización administrativa en México: Entre la tradición y el cambio. Foro Internacional 200, 50 (2), 393-421.

Prats i Català, J. (2005). De la burocracia al management, del management a la gobernanza. Las transformaciones de las administraciones públicas de nuestro tiempo. Madrid: Instituto Nacional de Administración Pública.

Presidencia de la Nación. (2016). El estado del Estado. Diagnóstico de la Administración Pública en diciembre de 2015. Disponible en https:// www.casarosada.gob.ar/elestadodelestado/docs/el_estado_del_estado. pdf [27-06-2020].

. (sin fecha). Portal de Turnos. Disponible en https://www. argentina.gob.ar/turnos [11-05-2019].

Ramírez Brouchoud, M. (2009). Las reformas del Estado y la administración pública en América Latina y los intentos de aplicación del New Public Management. Estudios Politicos, 34, 115-141.

Ramos, C. y Casa, M. (2018). Los procesos de reforma y modernización administrativa del Estado uruguayo desde la Oficina de Planeamiento y Presupuesto de la Presidencia de la República (Documento online N52). Montevideo: Programa de Historia Económica y Social, Facultad de Ciencias Sociales, Universidad de la República Constituyente. Disponible en http://cienciassociales.edu.uy/unidadmultidisciplinaria/ wpcontent/uploads/sites/6/2018/08/DT_PHES_No-52-ConradoRamos-y-Mauro-Casa.pdf [16-05-2019].

Ramos, C. y Scrollini, F. (2013). Los nuevos acuerdos entre políticos y servidores públicos en la Alta Dirección Pública en Chile y Uruguay. Revista Uruguaya de Ciencia Política, 22 (1), 11-36.

Secretaría de Modernización, Presidencia de la Nación. (2019). Guía de bienvenida al Estado. Disponible en http://ftp2.errepar.com/ bo/2019/02/04/R135anexo.pdf [27-06-2020]

Vommaro, G. (2015). Contribución a una sociología política de los partidos. Los mundos sociales de pertenencia y las generaciones políticas de PRO. En Vommaro, G. y Morresi, S. (Orgs.) "Hagamos equipo". PRO y la construcción de la nueva derecha en Argentina. Los Polvorines: UNGS. 
- (2016). Los partidos y sus mundos sociales de pertenencia: repertorios de acción, moralidad y jerarquías culturales en la vida política. En Vommaro, G. y Gené, M. (Comps.) La vida social del mundo politico. Los Polvorines: UNGS.

. (2017). La larga marcha de Cambiemos. Buenos Aires:

Siglo XXI.

Normas Citadas

Decreto N434/2016. Boletín Oficial de la República Argentina, Buenos Aires, Argentina.

Decreto Nº513/2017. Boletín Oficial de la República Argentina, Buenos Aires, Argentina.

Decreto N561/2016. Boletín Oficial de la República Argentina, Buenos Aires, Argentina.

Decreto N801/2018. Boletín Oficial de la República Argentina, Buenos Aires, Argentina.

Recibido: 30-05-2019

Aceptación de la versión final: 01-06-2020 